Standfast, A. F. B. (1951). J. gen. Microbiol. 5, 531-545.

\title{
The Phase I of Haemophilus pertussis
}

\author{
By A. F. B. STANDFAST \\ The Lister Institute of Preventive Medicine, Elstree, Hertfordshire
}

\begin{abstract}
SUMMARY: An examination of freshly isolated Haemophilus pertussis strains for agglutinability, growth requirements, haemagglutination, virulence for mice, alum precipitability and protective properties shows that each of these characters varies quantitatively, and furthermore that they vary independently. The presence of one strongly marked character is no indication that another character will be strongly marked or even present. Not all strains necessarily have the characters to be expected in freshly isolated strains; one or possibly more may be missing. On subculture of the strains on Bordet-Gengou media the order in which these characters degenerate or are lost and the rate at which they are lost differs with the strain. Agglutinability and agglutinogen content vary considerably in freshly isolated strains, and therefore the expression 'agglutinates to titre' cannot be considered as a criterion of a Phase I organism. The obvious complexity of the serology of organisms within 'Phase I' suggests that this term has served its useful purpose and should now be dropped as a description of a certain type of strain. The term 'Smooth', which indicates the possession of the antigenic components commonly associated with the pathogenic state of the organism, is preferable.
\end{abstract}

Leslie \& Gardner (1931) analysed thirty-two strains of Haemophilus pertussis by agglutination and agglutinin absorption and found that they fell into four well-marked groups which they called Phases I, II, III and IV. They suggested that Phases I and II probably correspond to the smooth (S) and Phases III and IV to the rough $(\mathbf{R})$ phase of other bacteria. This work was confirmed by Lawson (1939) with respect to Phases I, III and IV but he did not find any strains in Phase II. He stated, however, that 'there are undoubtedly other intermediate stages in the dissociation process, their number dependent on the strain of the organism and its environmental condition', and suggested that the degradation proceeds gradually, often making it difficult to determine the border-line between the phases.

The investigation of $\boldsymbol{H}$. pertussis has tended to proceed along one of two lines; either the investigation of the agglutinogenic relationship of the phases, as made by Flosdorf, Dozois \& Kimball (1941), who presented evidence that variation is even more complex in minor relationships than former workers had found, or the characterization of Phase I organisms in the hope of finding a single character which would clearly distinguish organisms in this phase.

What then is Phase I, and are all organisms in Phase I identical? Historically Phase I was defined serologically, but recent work (Smolens, McLaren, McAleer \& Flavell, 1947; Kendrick, Updyke \& Eldering, 1949; Cohen, 1949) has shown that freshly isolated strains may vary considerably in their agglutinogen content, and that a small number of typical strains are of consistently low agglutinability. Leslie \& Gardner implied, though they did not 
state it, that Phase I organisms only grow on Bordet-Gengou medium while Phases III and IV will grow on agar.

Lawson (1939) tabulated other characters, by which he distinguished the main phases, and later workers added more characters usually differentiating even more clearly Phase I from Phase IV; e.g. Burnet \& Timmins (1937) used virulence for mice by the intranasal route, Kendrick et al. (1949) virulence for mice by the intracerebral route, Keogh \& North (1948) haemagglutinin, Ungar \& Muggleton (1949) alum precipitability and bile solubility. These investigations, while they have added to our knowledge of Phase I, have not made it any easier to define. Usually the workers were interested in the selection of strains optimal for some such purpose as vaccine manufacture, and have implied or even stated that the presence or assay of one character in a strain can be taken as a measure of another character (e.g. Smolens et al., 1947, Keogh \& North, 1948, Ungar \& Muggleton, 1949). My investigation (Standfast, 1951) of the virulence for mice by the intranasal route and its correlation with certain other factors showed that when a large number of strains were examined there was little if any correlation between some of the characters of freshly isolated $H$. pertussis. It was felt that a re-examination of the main characters of Phase I was worth while in the hope that a more certain definition of Phase I might emerge. The characters used by most workers for differentiating strains are: (a) growth requirements, (b) agglutination and agglutinin absorption, $(c)$ virulence, $(d)$ protective antigenicity, $(e)$ haemagglutinin, $(f)$ alum precipitation and bile solubility, and to some extent $(g)$ morphology. In the experiments described in this paper about 100 strains of $H$. pertussis freshly isolated from clinical cases of whooping cough were examined for these characters.

\section{MATERIAL AND METHODS}

Strains. Strains of $H$. pertussis were freshly isolated from patients with whooping cough, the first subculture from the original cough or swab plate being sent to the laboratory. All strains agglutinated with sera prepared against freshly isolated $H$. pertussis strains. They consisted of typical small Gram-negative cocco-bacilli. There was some variation in size from strain to strain, certain strains being smaller, $0.5-0.6 \mu . \times 0 \cdot 3-0.4 \mu$, whereas others measured $0.7-0.8 \mu . \times 0 \cdot 4-0.5 \mu$. This size variation was on the whole consistent in the strain, and though on some batches of Bordet-Gengou medium the 'smaller' strains grew rather 'larger', this increase in size was not permanent. There was no correlation between size and any other character. After prolonged subculture on laboratory media all strains tend to become larger; but the strains examined all remained cocco-bacilli and did not become 'coliform' in size even after subculture on blood agar.

Medium. Bordet-Gengou agar was used, containing $1 \%$ Difco Proteose peptone (Baird and Tatlock Ltd., London) and $33 \%$ horse blood. Nutrient agar was prepared from horse meat digest, to which $10 \%$ horse blood was added to make blood agar.

A heavy inoculum on a bent glass rod was rubbed over half the BordetGengou plate, then carried over to the whole of the blood plate, then the whole 
of the nutrient agar plate and then the second half of the Bordet-Gengou plate. In all cases both halves of the Bordet-Gengou plate showed conflucnt growth after $24 \mathrm{hr}$. at $35^{\circ}$, indicating that there was an adequate inoculum on the blood agar and nutrient agar plates. There was never any growth on the agar plates after 5 days at $35^{\circ}$. Any growth on a blood agar plate was subcultured on a second blood agar plate, and only if this grew was growth considered positive on blood agar. On several occasions though growth occurred on the first blood agar plate it was not obtained on the second, indicating perhaps that the growth on the first plate was due to essential metabolites carried over with the inoculum.

Agglutination test. All agglutination tests were carried out in tubes, incubated at $55^{\circ}$ in a water-bath for $4 \mathrm{hr}$. and then stood at room temperature overnight. The titre is the reciprocal of the highest dilution which shows obvious agglutination with $\mathrm{a} \times \mathbf{3}$ hand-lens.

Sera were prepared in rabbits given three doses of $10^{9}$ formalized bacilli subcutaneously followed by three doses of $10^{9}$ living bacilli intravenously at weekly intervals.

Agglutinin absorptions were carried out by the method of Smolens et al. (1947) with certain modifications. A suspension of bacteria of any desired wet weight in a volume of $1 \mathrm{ml}$. were added to $1 \mathrm{ml}$. of a 1/250 dilution of antiserum, mixed and incubated for $2 \mathrm{hr}$. at $55^{\circ}$ and then placed in the refrigerator overnight. Next morning the tubes were centrifuged and $0.5 \mathrm{ml}$. of dilutions of the supernatant were added to $0.5 \mathrm{ml}$. of the test suspension, incubated for $4 \mathrm{hr}$. at $55^{\circ}$ and then stood at room temperature overnight. Serum controls were mixed with saline. The absorption titre was taken as the mg. wet weight of the strain required to absorb $90 \%$ of the agglutinin.

Virulence tests. Intranasal virulence was titrated by the technique of Burnet \& Timmins (1937). Briefly four doses of 100, 10, 1 and $0 \cdot 1$ million were each instilled intranasally into a group of ten mice kept under standardized conditions.

Intracerebral virulence was titrated by the method of Kendrick et al. (1949) using groups of ten mice on each dose. Mice of the strain $\mathrm{Cl}$. used in these laboratories required doses about ten times greater than the strain of American mice, a few of which were available for comparative purposes.

The LD 50 of each strain was calculated by the method of Reed \& Muench (1938).

Haemagglutinin tests. Suspensions for the haemagglutination test were prepared in saline or Difco Casamino acids (Baird and Tatlock Ltd., London) and standardized to contain $10^{10}$ organisms/ml., and serial twofold dilutions were prepared from these suspensions. Red blood corpuscles (R.B.c.) were prepared by centrifuging $1 \mathrm{ml}$. of fowl's blood, washing the R.B.c. three times in saline and resuspending in $50 \mathrm{ml}$. of saline. This 'strong' suspension can be kept 3 or 4 days in the refrigerator; before use it is diluted $1 / 4$ with $0.85 \%$ saline. It was found that $0.5 \mathrm{ml}$. of this dilute suspension was the optimum when added to $0.25 \mathrm{ml}$. of bacterial suspension.

For the test $\mathbf{0 . 2 5} \mathrm{ml}$. of the dilution of bacterial suspension was placed in a $12 \times 55 \mathrm{~mm}$. tube, and $0.5 \mathrm{ml}$. of R.в.c. suspension added. The racks were shaken 
and incubated at $37^{\circ}$ for $1 \mathrm{hr}$. The tubes were then shaken and put in the refrigerator to allow the cells to settle before reading the result.

The titre is taken as the reciprocal of the final dilution of bacterial suspension which shows obvious agglutination of the R.B.c. by eye.

Protection tests. Vaccines, prepared on horse blood Bordet-Gengou agar, were killed with $0.2 \%$ Liq. Formaldehyd B.P. (1948) diluted to $10^{10} \mathrm{bacilli} / \mathrm{ml}$., and tested by the method of Kendrick, Eldering, Dixon \& Misner (1947). The ImD 50 calculated by the method of Reed \& Muench (1938).

Aluminium phosphate precipitation was carried out by the method of Ungar \& Muggleton (1949). Three-tenths ml. of $5 \% \mathrm{Na}_{2} \mathrm{HPO}_{4}$ followed by $1 \mathrm{ml}$. of $2 \%$ potassium alum was added to $4.0 \mathrm{ml}$. of suspension of $10^{10} \mathrm{bacilli} / \mathrm{ml}$. in saline containing $\mathbf{0 . 2} \%$ Liq. Formaldehyd, shaken and stood for $30 \mathrm{~min}$. before reading.

\section{EXPERIMENTAL}

\section{Growth requirements}

On various occasions groups of strains were plated on Bordet-Gengou agar, blood agar and nutrient agar.

One strain M7 grew abundantly on blood agar immediately after first isolation. Three cultures of this strain, all behaving in the same way, were obtained from a child in an outbreak of whooping cough in a children's ward. In all other respects this strain was typical (Table 1). This is the only strain in this series which grew, and grew profusely, on blood agar from first isolation.

Of the seventy-one strains tested, eight showed some growth on blood agar seeded with the 2nd, 3rd and 4th subculture on Bordet-Gengou. Viable counts

Table 1. Modification of characters of four strains of Haemophilus pertussis which grew on blood agar, during subculture on Bordet-Gengou or blood agar

\begin{tabular}{|c|c|c|c|c|c|c|c|c|c|c|c|}
\hline \multirow{2}{*}{ Strain } & \multirow{2}{*}{$\begin{array}{c}\text { Sub- } \\
\text { culture } \\
\text { growing } \\
\text { on blood } \\
\text { agar }\end{array}$} & \multicolumn{2}{|c|}{$\begin{array}{c}\text { Agglutination } \\
\text { titre }\end{array}$} & \multicolumn{2}{|c|}{$\begin{array}{l}\text { Alum } \\
\text { precipitability } \\
(\%)\end{array}$} & \multicolumn{2}{|c|}{$\begin{array}{l}\text { Haemagglu- } \\
\text { tination } \\
\text { titre }\end{array}$} & \multicolumn{2}{|c|}{ 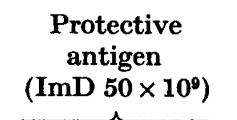 } & \multicolumn{2}{|c|}{$\begin{array}{c}\text { Virulence } \\
\text { (intranasal) } \\
\left(\text { LD 50 } \times 10^{6} \text { ) }\right.\end{array}$} \\
\hline & & $\mathbf{N}$ & & $\mathbf{N}$ & & $\mathbf{N}$ & & $\mathbf{N}$ & & $\mathbf{N}$ & \\
\hline M 7 & 1 & $\begin{array}{l}(3) \\
{[3]} \\
(\mathbf{1 7}) \\
{[17]}\end{array}$ & $\begin{array}{l}16,000 \\
16,000 \\
16,000 \\
16,000\end{array}$ & $\begin{array}{r}\dot{ } \\
(\mathbf{1 7}) \\
{[17]}\end{array}$ & $\begin{array}{r}\text { nt } \\
\text { nt } \\
100 \\
100\end{array}$ & $\begin{array}{l}(4) \\
{[4]} \\
: \\
\cdot\end{array}$ & $\begin{array}{c}0 \\
0 \\
\text { nt } \\
\text { nt }\end{array}$ & $\begin{array}{l}\dot{(17)} \\
{[17]}\end{array}$ & $\begin{array}{r}\text { nt } \\
\text { nt } \\
0 \cdot 20 \\
0 \cdot 21\end{array}$ & $\begin{array}{l}(\mathbf{3}) \\
{[\mathbf{3}]} \\
(\mathbf{1 7}) \\
{[\mathbf{1 7}]}\end{array}$ & $\begin{array}{r}1 \cdot 0 \\
1 \cdot 0 \\
1 \cdot 0 \\
27 \cdot 0\end{array}$ \\
\hline C 5467 & 4 & $\begin{array}{c}(9) \\
(4)+[5]\end{array}$ & $\begin{array}{r}16,000 \\
4,000\end{array}$ & $\begin{array}{c}(9) \\
(4)+[5]\end{array}$ & $\begin{array}{l}100 \\
100\end{array}$ & $\begin{array}{c}(2) \\
(4)+[5]\end{array}$ & $\begin{array}{r}48 \\
0\end{array}$ & • & $\begin{array}{l}\text { nt } \\
\text { nt }\end{array}$ & $\begin{array}{c}(2) \\
(4)+[5]\end{array}$ & $\begin{array}{l}35 \cdot 0 \\
40 \cdot 0\end{array}$ \\
\hline C 315 & 6 & $\begin{array}{c}(6) \\
(41) \\
(6)+[9] \\
(6)+[19]\end{array}$ & $\begin{array}{r}16,000 \\
16,000 \\
4,000 \\
2,000\end{array}$ & $\dot{\cdot}$ & $\begin{array}{l}\text { nt } \\
\text { nt } \\
\text { nt } \\
\text { nt }\end{array}$ & $\begin{array}{r}\text { Alway } \\
\text { negati } \\
\text { Alway } \\
\text { negati }\end{array}$ & & $\begin{array}{l}(15) \\
\dot{(6)}+[9] \\
\dot{\cdot}\end{array}$ & $\begin{array}{c}4 \cdot 0 \\
\text { nt } \\
5 \cdot 0 \\
\text { nt }\end{array}$ & $\begin{array}{c}(9) \\
(6)+[ \\
\dot{\cdot}\end{array}$ & $\begin{array}{c}5 \cdot 0 \\
\text { nt } \\
4 \cdot 0 \\
\text { nt }\end{array}$ \\
\hline C 407 & 7 & $\begin{array}{l}(\mathbf{1 5}) \\
(\mathbf{3 2 )} \\
(\mathbf{8})+[7]\end{array}$ & $\begin{array}{l}32,000 \\
32,000 \\
16,000\end{array}$ & $\dot{.}$ & $\begin{array}{l}\text { nt } \\
\text { nt } \\
\text { nt }\end{array}$ & $\begin{array}{l}(\mathbf{1 5}) \\
(\mathbf{3 2}) \\
(\mathbf{8})+[\mathbf{7}] \\
(\mathbf{8})+[\mathbf{1 4}]\end{array}$ & $\begin{array}{r}12 \\
12 \\
0 \\
0\end{array}$ & $\begin{array}{c}(8) \\
\stackrel{\dot{+}}{[}[7] \\
\dot{\cdot}\end{array}$ & $\begin{array}{c}0 \cdot 85 \\
\text { nt } \\
1 \cdot 6 \\
\text { nt }\end{array}$ & $\begin{array}{l}(\mathbf{1 5}) \\
(\mathbf{3 2}) \\
(\mathbf{8})+[\mathbf{7}] \\
(\mathbf{8})+[\mathbf{1 4}]\end{array}$ & $\begin{array}{c}0.63 \\
1 \cdot 0 \\
1 \cdot 6 \\
110 \cdot 0\end{array}$ \\
\hline
\end{tabular}

$\mathbf{N}$, number of subculture. ( ), on Bordet-Gengou. [ ], on blood agar. (4) $+[5]$, 5th serial subculture on blood agar following four subcultures on Bordet-Gengou. nt, not tested. 
were made on Bordet-Gengou and blood agar on three of these strains. The ratio of colony counts on blood agar to Bordet-Gengou were 1:340 million, $1: 940$ million and 1:1270 million.

\section{Stability of strains with respect to growth requirements on continued subculture}

A group of twenty strains were plated daily on Bordet-Gengou agar and at intervals on blood agar. Five showed some growth on blood agar after 11th, 12th, 12th, 16th and 25th subcultures on Bordet-Gengou. The remaining fifteen strains did not grow on blood agar after sixty subcultures on BordetGengou.

Another group of seventeen strains were plated daily on Bordet-Gengou agar for over 200 subcultures, and once a week on blood agar. Growth appeared on blood agar from seven of these strains after 38th, 114th, 190th, 197th, 200th, 203rd, and 211th subcultures on Bordet-Gengou. The other ten strains did not acquire the capacity to grow on blood agar.

The twelve strains mentioned above and the eight strains growing on blood agar soon after first isolation all produced from 10 to 100 isolated colonies on the first blood agar plate after $1-5$ days at $35^{\circ}$. If these strains are identical with the strain isolated by Pollock (1947) it would seem that some (eight out of seventy-one) freshly isolated $\boldsymbol{H}$. pertussis carry the variant. It may, however, arise spontaneously after any number of subcultures on laboratory media in some strains, and eventually all strains may produce it. One strain (C 407) of a group of five which were plated daily on blood agar suddenly produced this variant

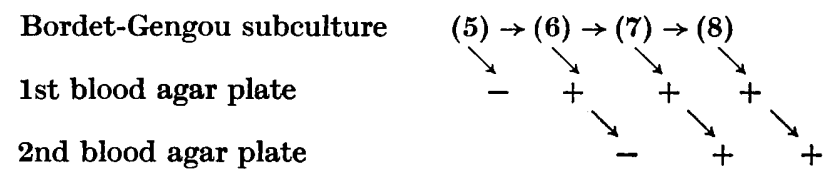

the other four remaining negative. Viable counts of subcultures 7 and 8 gave a ratio of variant to parent of $1: 800 \times 10^{6}$ on both occasions.

In other respects the strains carrying this variant appeared to be typical Phase I organisms (Table 1); the variant behaved as the parent strain for a few subcultures on blood agar, but on further culture rapidly lost some of its characters (see Table 1). In this respect it is interesting to note that the protective antigen, as measured by the ability to protect mice against an intracerebral challenge, was one of the more stable characters.

\section{Agglutination}

One strain was not agglutinable during the first four daily subcultures either by slide agglutination or by tube agglutination, but the 5 th and several subsequent subcultures were agglutinated to titre. Occasionally strains were found which did not agglutinate on the slide because of a pronounced pro-zone effect which was obvious in the tube agglutination and could be avoided by diluting the serum used for the slide test, when a positive agglutination was obtained. 
Table 2. Agglutination of 105 freshly isolated strains of Haemophilus pertussis by several sera prepared against freshly isolated strains

$\begin{array}{cc}\text { Titre } & \text { No. of strains } \\ \mathbf{1 6 , 0 0 0 - 3 2 , 0 0 0} & \mathbf{9 3} \\ \mathbf{8 , 0 0 0} & \mathbf{5} \\ \mathbf{4 , 0 0 0} & \mathbf{6} \\ \mathbf{2 , 0 0 0} & \mathbf{1}\end{array}$

All strains examined agglutinated with Phase I serum, usually but not always to a high titre. The tests on 105 freshly isolated strains in Table 2 show that a small number of strains are of consistently low agglutinability. Other workers have found similar strains (Smolens et al. 1947; Kendrick et al. 1949; Cohen, 1949). In a further examination five of these strains (Table 3) did not differ appreciably from strains of high agglutinability in any other way.

Table 3. General characters of five strains of Haemophilus pertussis of low agglutinability

\begin{tabular}{|c|c|c|c|c|c|c|}
\hline $\begin{array}{l}\text { Strain no. and } \\
\text { subculture }\end{array}$ & $\begin{array}{l}\text { Growth on } \\
\text { blood agar }\end{array}$ & $\begin{array}{l}\text { Agglutina- } \\
\text { tion } \\
\text { titre }\end{array}$ & $\begin{array}{c}\text { Alum } \\
\text { precipitability } \\
(\%)\end{array}$ & $\underset{\text { titre }}{\text { Haemagglutinin }}$ & $\begin{array}{c}\text { Protective } \\
\text { antigen } \\
(\operatorname{ImD} \mathbf{5 0} \times \mathbf{1 0})\end{array}$ & $\begin{array}{c}\text { Virulence } \\
\text { (intranasal) } \\
\left(\text { LD 50 } 5 \mathbf{1 0}^{6}\right)\end{array}$ \\
\hline L 51-7 & - & 8000 & nt & 96 & $0 \cdot 85$ & $1 \cdot 0$ \\
\hline L 67-7 & - & 8000 & 100 & 12 & 0.71 & nt \\
\hline W 1276-3 & - & 4000 & 100 & 24 & nt & $0 \cdot 1$ \\
\hline W 1505-3 & - & 4000 & 100 & nt & nt & $45 \cdot 0$ \\
\hline W 1506-3 & - & 2000 & 100 & 12 & $0 \cdot 45$ & nt \\
\hline
\end{tabular}

$\rightarrow$, negative. nt, not tested. Compare also Table 7, strain P 34-7 and P 54-15.

Antisera were prepared against four freshly isolated strains, two of high agglutinability and two of low agglutinability and subjected to cross-agglutination and cross-absorption tests (Table 4). There was no difference in the major antigens of the two types of strain.

The work of Smolens et al. (1947) showed that strains can differ widely in their content of agglutinogen. In general, they found that strains high in

Table 4. Cross-absorption tests of two strains of Haemophilus pertussis; one $(H)$ of high agglutinability, and the other $(L)$ of low agglutinability

\begin{tabular}{|c|c|c|c|c|c|c|}
\hline \multirow[b]{3}{*}{ Against } & \multicolumn{2}{|l|}{ Serum } & \multicolumn{4}{|c|}{ Titres after absorption by } \\
\hline & \multirow{2}{*}{$\begin{array}{c}\text { Absorbed } \\
\text { by }\end{array}$} & \multirow{2}{*}{$\begin{array}{c}\text { Tested } \\
\text { with } \\
\text { suspension }\end{array}$} & \multicolumn{4}{|c|}{ Absorbing dose (mg. wet weight) } \\
\hline & & & $\mathbf{0} \cdot \mathbf{0}$ & $\mathbf{2 \cdot 5}$ & $5 \cdot 0$ & $10 \cdot 0$ \\
\hline \multirow[t]{4}{*}{$\mathbf{H}$} & $\mathbf{H}$ & $\mathbf{H}$ & 32,000 & 4,000 & 50 & nt \\
\hline & & $\mathbf{L}$ & 4,000 & 4,000 & $\mathbf{0}$ & nt \\
\hline & $\mathbf{L}$ & $\mathbf{H}$ & 32,000 & nt & 2,000 & 100 \\
\hline & & $\mathbf{L}$ & 4,000 & nt & 1,000 & 100 \\
\hline \multirow[t]{4}{*}{$\mathbf{L}$} & $\mathbf{H}$ & $\mathbf{H}$ & 16,000 & 2,000 & $\mathbf{0}$ & nt \\
\hline & & $\mathbf{L}$ & 4,000 & 1,000 & $\mathbf{0}$ & nt \\
\hline & $\mathbf{L}$ & $\mathbf{H}$ & 16,000 & nt & 100 & $\mathbf{0}$ \\
\hline & & $\mathbf{L}$ & 4,000 & nt & 100 & $\mathbf{0}$ \\
\hline
\end{tabular}


absorbing power were agglutinated to a high titre, and strains of low absorbing power to a low titre, but there were several exceptions. In my experiments seven strains agglutinating to $1 / 16,000-1 / 32,000$ had absorbing potencies from 2.5 to $40.0 \mathrm{mg}$; ; a range very similar to the $1.3-10 \mathrm{mg}$. reported by Smolens. Two strains of low agglutinability were found, one was agglutinated to a titre of 4000 and had an absorption titre of $2.5 \mathrm{mg}$., and with the other the corresponding figures were 8000 and $>20 \mathrm{mg}$. Cross-absorption tests with these strains showed that strains of high absorbing power absorb a lot of agglutinin from sera prepared with strains of high or low agglutinability and strains of low absorbing power absorb little from either type of sera. Agglutination, before and after absorption, of heterologous and homologous suspension showed that only one major antigen was involved, so that all these strains must be regarded as agglutinating to titre with Phase I serum. In this respect these strains differed from certain strains of lowered agglutinability obtained by subculture in which another antigen appeared which was demonstrated by crossabsorption tests.

From my experiments and those of Smolens et al. we must conclude that the agglutinability of cells and their agglutinogen content vary independently.

\section{Stability of Phase I agglutinogen of strains on continued subculture}

Six strains subcultured daily on Bordet-Gengou media were tested at intervals by agglutination and agglutinin absorption. By chance they were all (Table 9) strains of high agglutinability, three of them (L 46, L 49 and L 54) had a high absorbing power (titre $2.5 \mathrm{mg}$.), one (L 57) a very low absorbing power (titre $c .40 .0 \mathrm{mg}$.). All the strains immediately lost absorbing power but not, however, in parallel with the loss of agglutinability, which occurred at different times and at different rates in four of the six strains. Furthermore, apart from the general degeneration of these strains, neither absorbing powers nor agglutinability were lost in parallel with any other character.

One of the strains, L 54, was examined by cross-absorption tests. Subculture 162 differed markedly from the freshly isolated strains of low agglutinability reported above in that another antigen was easily demonstrated which was present neither in subculture 15 nor in any freshly isolated strains of high or low agglutinability. This is presumably the Phase II or Phase III antigen.

\section{Virulence}

The virulence (LD 50) for mice by the intranasal route has been dealt with in detail elsewhere (Standfast, 1951). Briefly forty-three strains were tested at the 2nd or 3rd subculture; thirteen of these strains had a LD 50 of less than 1 million, seven between 1 million and 5 million, nine between 5 million and 25 million, thirteen between 25 million and 125 million and one more than 125 million; in fact the LD 50 ranged from 0.1 million to 152 million. These strains grew only on Bordet-Gengou medium and agglutinated with Phase I serum to a high titre.

The eight strains (p. 534) which carried (2nd-4th subculture) the variant growing on blood agar at first isolation were in no way abnormal in virulence. 
The virulence of cultures grown on blood agar seems to depend on the number of times they have been subcultured, but varies somewhat from strain to strain (see Table 1), but the loss in virulence is not contemporaneous with the ability to grow on blood agar.

Kendrick et al. (1949) examined seventy smooth cultures for virulence by the intracerebral route and found that they fell into two groups, those having an end-point of $10^{4}-10^{7}$ and those having an end-point of $10^{3}$ or less. The LD 50 of the fifteen strains which fell into the latter group ranged from 100 to 1000 organisms.

I was able to test thirty-one strains for virulence by the intranasal route and the intracerebral route in parallel (Table 5). There was a wide variation in the LD 50 by the intracerebral route ranging from $<10^{3}$ to $10^{9}$.

Table 5. Comparison of virulence by intranasal and intracerebral routes of thirty-one freshly isolated strains of Haemophilus pertussis

(Numbers of strains in each group.)

\begin{tabular}{cccc}
$\begin{array}{c}\text { Intracerebral } \\
\text { LD 50 }\end{array}$ & \multicolumn{3}{c}{ Intranasal LD 50 in millions } \\
${$\cline { 2 - 2 }$} }$ & $<1 \cdot 0$ & $1 \cdot 0<10 \cdot 0$ & $10 \cdot 0<100 \cdot 0$ \\
$10^{4},<10^{5}$ & 4 & 1 & 0 \\
$10^{5},<10^{6}$ & 0 & 2 & 0 \\
$10^{6},<10^{7}$ & 8 & 0 & 1 \\
$>10^{7}$ & 8 & 2 & 2 \\
& 1 & 2 & 0
\end{tabular}

Virulence by the intercerebral, route and virulence by the intranasal route depend on different factors. First, there is no direct correlation between results by the two routes (Table 5); secondly, though the LD 50 by the intranasal route is dependent on the weight and age of the mice (Standfast, 1951) this factor does not influence the LD 50 by the intracerebral route unless very small mice are used.

The intraperitoneal route is more a measure of the toxin content of the organisms than of their virulence. Nine strains were tested in parallel by the intranasal, intracerebral and intraperitoneal route; by the intranasal route the LD 50 varied between $0.26 \times 10^{6}$ and $15.5 \times 10^{6}$ - a 60 -fold range-by the intracerebral route between $0.18 \times 10^{6}$ and $2.5 \times 10^{6}-$ a 14-fold range-and by the intraperitoneal route between $280 \times 10^{6}$ and $800 \times 10^{6}-\mathrm{a} 2 \cdot 85$-fold range. There was no correlation between high and low value by any of these routes with any particular strain. Table 6 shows the highest and lowest values for each route for the strains tested. The results by the three routes are obviously dependent on different factors and vary independently.

\section{Stability of virulence in strains on continued subculture}

On subculture on Bordet-Gengou medium some strains retained their virulence during a large number of subcultures while others lost it quickly. Virulence once lost was not recovered by further subculture, but could sometimes be partly recovered by mouse passage. Table 9 shows some examples of 
Table 6. Comparison of virulence by three routes of five strains of Haemophilus pertussis

\begin{tabular}{lccc} 
& \multicolumn{3}{c}{ LD 50 in millions } \\
Strain & $\overbrace{\text { Intranasal }}$ & Intracerebral & Intraperitoneal \\
L 5,743 & $0 \cdot 26$ & $0 \cdot 18$ & 655 \\
L 5,754 & $15 \cdot 5$ & $0 \cdot 24$ & 640 \\
C 10,487 & $1 \cdot 0$ & $1 \cdot 0$ & 800 \\
C 19,767 & $2 \cdot 1$ & $1 \cdot 6$ & 280 \\
C 19,764 & $3 \cdot 3$ & $2 \cdot 5$ & 320
\end{tabular}

stable and unstable strains. Strains L 54 and L 58 retained their full virulence for 162 and 132 subcultures; the other four strains all lost virulence, but at different times and to a different degree. Strain $\mathrm{L} 46$ has lost virulence most rapidly having an LD 50 of 39 million, at the 39th subculture while strain L 49 maintained its original virulence for at least 145 subcultures and then degenerated. Another strain, C7988, behaved like L 46, losing virulence rapidly, an LD 50 of 4.5 million at subculture 2 fell to 46.0 million by subculture 12. Other strains, such as C2188, behave like $\mathrm{L} 49$, tested on five occasions, up to subculture 206, it had at each test an LD 50 of less than 0.2 million. But at the 218th subculture the LD 50 was 12.0 million and at the 286th subculture, 10.0 million. This drop in virulence followed by stability at the raised figure, as shown by strain $\mathrm{L} 46$ (Table 9 ) and $\mathrm{C} 2188$ but not by L 45, suggests the sudden loss of one of the factors which determines virulence.

\section{Haemagglutination}

Seventy-one freshly isolated strains were tested for haemagglutinin on several occasions and gave consistent titres as follows: twenty strains 1/196 to $1 / 96$, twenty-nine strains $1 / 48$ to $1 / 24$, eight strains $1 / 12$ to $1 / 6$, three strains showed traces only at $1 / 6$ or $1 / 3$ and eleven strains were invariably negative. As shown in a previous paper (Standfast, 1951) there is no correlation between haemagglutinin and virulence measured by the intranasal route nor does haemagglutinin tie up with any of the other characters. Table 7 shows the main characters of twelve strains arranged in order of haemagglutinin production. There is no association with any of the other characters (see also Table 9).

\section{Stability of haemagglutinin in strains on continued subculture}

Haemagglutinin appears to be one of the more labile characters of $H$. pertussis. Seventeen strains were subcultured daily on Bordet-Gengou medium and tested at various subcultures for haemagglutinin. Table 8 shows four characteristic results.

\section{Protective antigenicity}

Single strain vaccines were prepared from eighteen freshly isolated strains and tested for protective potency in mice against a reference vaccine. Most of these vaccines were tested on several occasions and an average $\operatorname{ImD} 50$ obtained. Their $\operatorname{ImD} 50$ varied from $0.21 \times 10^{9}$ to $1.32 \times 10^{9}$. The errors of the test are 
Table 7. A comparison of the characters of twelve strains of Haemophilus pertussis, arranged in order of their haemagglutination titres

\begin{tabular}{|c|c|c|c|c|c|c|c|}
\hline $\begin{array}{l}\text { Strain and } \\
\text { subculture }\end{array}$ & $\begin{array}{c}\text { Haemagglu- } \\
\text { tination } \\
\text { titre }\end{array}$ & $\begin{array}{c}\text { Agglutination } \\
\text { titre }\end{array}$ & $\begin{array}{c}\text { Alum } \\
\text { precipitability } \\
(\%)\end{array}$ & $\begin{array}{l}\text { Growth on } \\
\text { blood agar }\end{array}$ & $\begin{array}{c}\text { Protective } \\
\text { antigen } \\
\operatorname{ImD} 50 \times 10^{9}\end{array}$ & $\begin{array}{c}\text { Virulence } \\
\text { (intranasal) } \\
\text { LD } 50 \times 10^{6}\end{array}$ & $\begin{array}{r}\text { Quick } \\
\text { killing } \\
\text { factor }\end{array}$ \\
\hline P 37-7 & 96 & 32,000 & 100 & - & $0 \cdot 48$ & $1 \cdot 0$ & - \\
\hline P 34-7 & 96 & $\mathbf{8 , 0 0 0}$ & 100 & - & 0.85 & $9 \cdot 0$ & - \\
\hline P 33-22 & 48 & $\mathbf{3 2 , 0 0 0}$ & 100 & - & $0 \cdot 62$ & $8 \cdot 3$ & - \\
\hline P 43-43 & 48 & 16,000 & 100 & - & $0 \cdot 37$ & $66 \cdot 0$ & - \\
\hline P 37-9 & $\mathbf{2 4}$ & 32,000 & 100 & nt & 1.07 & $1 \cdot 7$ & + \\
\hline P 54-15 & 24 & 4,000 & 100 & - & $1 \cdot 32$ & $4 \cdot 6$ & + \\
\hline P 53-8 & 24 & $\mathbf{3 2 , 0 0 0}$ & 100 & + & $0 \cdot 65$ & $\mathbf{3} \cdot \mathbf{0}$ & - \\
\hline P 32-22 & 12 & 32,000 & 100 & - & 0.58 & $9 \cdot 4$ & - \\
\hline P 42-43 & 12 & 32,000 & 100 & - & $1 \cdot 12$ & $34 \cdot 0$ & - \\
\hline P 31-10 & Trace & 16,000 & 100 & - & $0 \cdot 34$ & $0 \cdot 84$ & + \\
\hline P 26-5 & $\mathbf{0}$ & 32,000 & 100 & - & 0.57 & $0 \cdot 64$ & + \\
\hline P 27-5 & 0 & 32,000 & 100 & - & $1 \cdot 19$ & $0 \cdot 67$ & + \\
\hline
\end{tabular}

The above characters were tested on the same suspension for each strain; after the other tests had been carried out $1 / 10,000$ thiomersalyl was added and a sterile vaccine prepared for the mouse protection tests. Growth on blood agar: - , negative; +, positive; nt, not tested.

Table 8. Haemagglutination titres of four typical strains of Haemophilus pertussis subcultured daily on to fresh Bordet-Gengou medium Strain no.

\begin{tabular}{|c|c|c|c|c|c|c|c|c|c|c|}
\hline L 59 & $\mathbf{N}$ & $\begin{array}{r}4 \\
24\end{array}$ & $\begin{array}{l}10 \\
12\end{array}$ & $\begin{array}{r}15 \\
0\end{array}$ & $\begin{array}{r}25 \\
0\end{array}$ & . & . & . & . & . \\
\hline L 54 & $\mathbf{N}$ & . & $\begin{array}{r}9 \\
24\end{array}$ & $\begin{array}{l}15 \\
24\end{array}$ & $\begin{array}{c}24 \\
12\end{array}$ & $\begin{array}{r}33 \\
0\end{array}$ & $\begin{array}{r}39 \\
0\end{array}$ & . & . & • \\
\hline L $\mathbf{4 8}$ & $\mathbf{N}$ & $\begin{array}{r}5 \\
24\end{array}$ & . & $\begin{array}{l}17 \\
24\end{array}$ & $\begin{array}{l}20 \\
24\end{array}$ & $\begin{array}{r}29 \\
12\end{array}$ & $\begin{array}{l}40 \\
12\end{array}$ & $\begin{array}{r}53 \\
0\end{array}$ & $\begin{array}{r}69 \\
0\end{array}$ & . \\
\hline L 51 & $\mathbf{N}$ & $\begin{array}{r}2 \\
96\end{array}$ & $\begin{array}{r}7 \\
96\end{array}$ & $\begin{array}{l}16 \\
96\end{array}$ & $\begin{array}{l}23 \\
48\end{array}$ & $\begin{array}{l}34 \\
24\end{array}$ & $\begin{array}{l}42 \\
12\end{array}$ & $\begin{array}{l}52 \\
12\end{array}$ & $\begin{array}{r}70 \\
6\end{array}$ & $\begin{array}{r}84 \\
0\end{array}$ \\
\hline
\end{tabular}

$\mathbf{N}$, numbers of subculture. Compare also strains in Table 9.

such that it is doubtful if there is any significant difference in the potency of these vaccines. But between two vaccines picked from the extremes of the range there was a suggestion of a real difference in protective properties. In four tests of vaccine $\mathrm{C} 26,573$, the $\operatorname{ImD} 50$ was $0 \cdot 16,0.21,0.22$ and 0.26 , average $0 \cdot 21$, and of vaccine $L 57-5$, the $\operatorname{ImD} 50$ was $0.96,1 \cdot 27,1 \cdot 28,0 \cdot 2$, average $0 \cdot 93$.

There is no correlation between protective properties or any other Phase I character (see Tables 1, 7 and 9), this corroborates the findings of Kendrick and her co-workers who found no marked differences in protective properties of thirty-six smooth strains or any association between protection and relative degree of virulence as estimated by the intracerebral route.

\section{Stability of protective property of strains on continued subculture}

Vaccines were prepared at different subcultures from six strains which had been subcultured daily on Bordet-Gengou medium. Table 9 shows the average ImD 50's of the vaccines prepared from the different subcultures. There is a 
suggestion that the protective potency of some strains decline, though this is marked only in strain $\mathbf{L}$ 45. The protective property appears to be lost in different strains at different times and at different rates.

\section{Precipitation by aluminium phosphate}

Ungar \& Muggleton(1949) examined thirty-four freshly isolated strains, which agglutinated to high titre (1/8000 or more) with phase I serum, for precipitation with aluminium phosphate. Because all these strains precipitated completely they concluded that precipitation with aluminium phosphate provides a quick method for distinguishing virulent Phase I strains from strains which had deteriorated. My experiments are not entirely in agreement; the majority of freshly isolated strains are positive and lose this character when they deteriorate but several freshly isolated strains which were otherwise typical were not completely precipitable, and certain strains which had lost or were losing some of their other characters were still completely precipitable with aluminium

Table 9. Comparison of six strains tested after varying number of subcultures

\begin{tabular}{|c|c|c|c|c|c|c|c|c|c|c|}
\hline Strain & Character & $1-9$ & $10-25$ & $26-50$ & $51-75$ & $76-100$ & $101-125$ & $186-150$ & $151-200$ & $200-225$ \\
\hline L 45 & $\begin{array}{l}\text { Agglutination titre } \\
\text { Agglutination absorption, mg. } \\
\text { Alum precipitability, \% } \\
\text { Growth on blood agar } \\
\text { Haemagglutination titre } \\
\text { Protective antigen, ImD } 50 \\
\text { Virulence (intranasal), LD } 50\end{array}$ & $\begin{array}{r}32,000 \\
5 \cdot 0 \\
100 \\
- \\
48 \\
0 \cdot 41 \\
0.64\end{array}$ & $\begin{array}{r}32,000 \\
10 \cdot 0 \\
100 \\
- \\
48 \\
0 \cdot 77 \\
9 \cdot 4\end{array}$ & $\begin{array}{r}32,000 \\
100 \\
- \\
48 \\
1 \cdot 15 \\
34 \cdot 0\end{array}$ & $\begin{array}{l}16,000 \\
15 \cdot 0 \\
\dot{-} \\
120 \\
65 \cdot 0\end{array}$ & $\begin{array}{r}8,000 \\
\cdot \quad 0 \\
-\quad 0 \\
\cdot{ }^{\circ}\end{array}$ & $\begin{array}{l}\dot{1} \\
+ \\
\dot{0} \\
\dot{0}\end{array}$ & $\begin{array}{l}0 \\
\dot{5} \\
\dot{ }\end{array}$ & $\begin{array}{c}0 \\
>40 \cdot 0 \\
+ \\
+ \\
\dot{3} \cdot 32 \\
80 \cdot 0\end{array}$ & $\dot{:}$ \\
\hline L 46 & $\begin{array}{l}\text { Agglutination titre } \\
\text { Agglutination absorption, mg. } \\
\text { Alum precipitability, \% } \\
\text { Growth on blood agar } \\
\text { Haemagglutination titre } \\
\text { Protective antigen, ImD } 50 \\
\text { Virulence (intranasal), LD } 50\end{array}$ & $\begin{array}{r}16,000 \\
2 \cdot 5 \\
100 \\
- \\
48 \\
0.71 \\
0.46\end{array}$ & $\begin{array}{r}16,000 \\
3 \cdot 75 \\
100 \\
-\quad \\
48 \\
0 \cdot 98 \\
8 \cdot 3\end{array}$ & $\begin{array}{r}16,000 \\
5 \cdot 0 \\
100 \\
-\quad \\
48 \\
0 \cdot 67 \\
66 \cdot 0\end{array}$ & $\begin{array}{l}16,000 \\
: \\
: \\
:\end{array}$ & $\begin{array}{c}16,000 \\
: \\
\frac{5}{6} \\
.\end{array}$ & $\begin{array}{r}16,000 \\
20 \cdot 0 \\
100 \\
- \\
1 \cdot 19 \\
66 \cdot 0\end{array}$ & $\dot{i}$ & $\begin{array}{l}\dot{ } \\
\dot{-} \\
\dot{.}\end{array}$ & $\begin{array}{l}\quad 0 \\
100 \\
+ \\
:\end{array}$ \\
\hline L 49 & $\begin{array}{l}\text { Agglutination titre } \\
\text { Agglutination absorption, mg. } \\
\text { Alum precipitability, \% } \\
\text { Growth on blood agar } \\
\text { Haemagglutination titre } \\
\text { Protective antigen, ImD } 50 \\
\text { Virulence (intranasal), LD } 50\end{array}$ & $\begin{array}{r}16,000 \\
100 \\
- \\
48 \\
0 \cdot 63 \\
0 \cdot 26\end{array}$ & $\begin{array}{r}16,000 \\
2 \cdot 5 \\
100 \\
-\quad \\
24 \\
0 \cdot 63 \\
0 \cdot 64\end{array}$ & 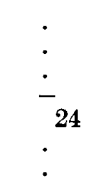 & $\begin{array}{l}16,000 \\
: \\
- \\
24 \\
\dot{1} \cdot 6\end{array}$ & $\begin{array}{l}\dot{100} \\
- \\
\dot{5}\end{array}$ & $\begin{array}{l}16,000 \\
10 \cdot 0 \\
. \\
- \\
.\end{array}$ & $\begin{array}{r}16,000 \\
100 \\
-\quad 0 \\
0.87 \\
3.0\end{array}$ & $\begin{array}{r}16,000 \\
20 \cdot 0 \\
100 \\
-\quad 0 \\
1 \cdot 35 \\
26 \cdot 0\end{array}$ & $\begin{array}{l}0 \\
\dot{1} 100 \\
- \\
\dot{5} \\
\dot{ }\end{array}$ \\
\hline L 54 & $\begin{array}{l}\text { Agglutination titre } \\
\text { Alum precipitability, \% } \\
\text { Growth on blood agar } \\
\text { Haemagglutination titre } \\
\text { Protective antigen, ImD 50 } \\
\text { Virulence (intranasal), LD 50 }\end{array}$ & $\begin{array}{r}16,000 \\
100 \\
-\quad 24 \\
0.71 \\
1 \cdot 2\end{array}$ & 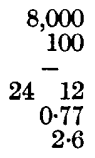 & $\begin{array}{l}8,000 \\
+ \\
+\end{array}$ & $\dot{i}_{0}$ & $\begin{array}{l}100 \\
+ \\
\dot{ } \\
\dot{ }\end{array}$ & $\begin{array}{l}8,000 \\
100 \\
+ \\
: \\
:\end{array}$ & $\begin{array}{l}8,000 \\
100 \\
+ \\
: \\
:\end{array}$ & $\begin{array}{l}2,000 \\
100 \\
+ \\
\dot{0} \cdot 78 \\
1.0\end{array}$ & $\dot{:}$ \\
\hline L 57 & $\begin{array}{l}\text { Agglutination titre } \\
\text { Agglutination absorption, mg. } \\
\text { Alum precipitability, \% } \\
\text { Growth on blood agar } \\
\text { Haemagglutination titre } \\
\text { Protective antigen, ImD } 50 \\
\text { Virulence (intranasal), LD } 50\end{array}$ & $\begin{array}{r}16,000 \\
c .40 \cdot 0 \\
100 \\
-\quad 24 \\
0.93 \\
0 \cdot 13\end{array}$ & $\begin{array}{l}16,000 \\
: \\
: \\
:\end{array}$ & $\begin{array}{l}\dot{\cdot} \\
\dot{2} \\
24 \\
\dot{0.53}\end{array}$ & $\begin{array}{r}16,000 \\
100 \\
-\quad 24 \\
\dot{0} \cdot 66\end{array}$ & $\begin{array}{l}16,000 \\
\dot{\cdot} \\
- \\
\cdot\end{array}$ & $\begin{array}{c}16,000 \\
>40 \cdot 0 \\
\therefore \\
\therefore\end{array}$ & 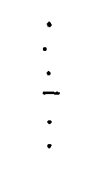 & $\begin{array}{c}16,000 \\
>40 \cdot 0 \\
100 \\
+ \\
i \cdot 27 \\
3 \cdot 0\end{array}$ & $\begin{array}{l}8,000 \\
\cdot 75 \\
+ \\
\cdot\end{array}$ \\
\hline L 58 & $\begin{array}{l}\text { Agglutination titre } \\
\text { Agglutination absorption, mg. } \\
\text { Alum precipitability, \% } \\
\text { Growth on blood agar } \\
\text { Haemagglutination titre } \\
\text { Protective antigen, ImD } 50 \\
\text { Virulence (intranasal), LD 50 }\end{array}$ & $\begin{array}{r}16,000 \\
5 \cdot 0 \\
100 \\
- \\
24 \\
1 \cdot 13 \\
9 \cdot 3\end{array}$ & $\begin{array}{l}16,000 \\
: \\
\therefore \\
:\end{array}$ & $\dot{:}$ & $\begin{array}{r}16,000 \\
10 \cdot 0 \\
100 \\
- \\
24 \\
.\end{array}$ & 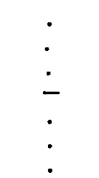 & $\begin{array}{c}16,000 \\
20 \cdot 0 \\
\therefore \\
- \\
.\end{array}$ & $\begin{array}{l}8,000 \\
c .40 \cdot 0 \\
100 \\
- \\
i \cdot 85 \\
10 \cdot 0\end{array}$ & $\begin{array}{c}8,000 \\
>40 \cdot 0 \\
100 \\
- \\
\dot{0} \cdot 95 \\
10 \cdot 0\end{array}$ & $\dot{:}$ \\
\hline
\end{tabular}


phosphate (Table 3, Table 9, strains L 45, L 46, L 49; see also Ungar \& Muggleton (1949), Table 3, strain 10,203).

In my experiments thirty-nine strains were tested at first isolation; thirtyfive precipitated completely, three to about $75 \%$ and one not at all.

\section{Stability of aluminium phosphate precipitability in strains on continued subculture}

Of forty-six strains, which had been subcultured in the laboratory on BordetGengou medium up to $\mathbf{1 0 0}$ daily subcultures and were still in Phase I by the other criteria, tested with aluminium phosphate forty-one were $100 \%$ positive, three were about $75 \%$ and two were negative.

Six strains subcultured daily on Bordet-Gengou medium for 225 days were tested at various intervals. In one of these strains there is a complete loss of precipitability from the 48th subculture, in another some loss by the 68th subculture, the other four strains were stable up to the last subculture tested (Table 9). Four variants growing on blood agar were tested after 9, 12, 13 and 13 subcultures on blood agar. These variants were no longer agglutinated to titre with Phase I serum but two were completely precipitated and two precipitated to about $75 \%$ (see also Table 1, strain C 5467).

\section{DISCUSSION}

When freshly isolated $H$. pertussis strains are examined to determine the main characters by which so-called Phase I organisms are distinguished from the other phases, three facts come to light. (1) Any one character varies quantitatively and it is therefore impossible, except by setting up an artificial boundary, to use any character qualitatively for definition. One cannot simply say that a certain strain is 'virulent' or 'agglutinates'. (2) Not all strains have all the characters which one normally expects in freshly isolated strain of $H$. pertussis. For example, the strain $\mathbf{M} 7$ in most characters was a typical $H$. pertussis strain, but from first isolation it could grow on blood agar. Portwood (1946), who investigated the catalase activity of $H$. pertussis, reported that fourteen of sixty-two smooth strains had no activity. (3) The main characters vary independently, and the presence of one character even strongly marked is no evidence that another character is also strongly marked or in fact present at all. In addition to evidence presented in the paper, Portwood (1946) reported that agglutination tests presented no evidence of differences in antigenic structure between strains with or without catalase activity.

On subculture, characters may degenerate or be lost in different strains at different times and in different orders. Diagrammatically we may view a strain of $\boldsymbol{H}$. pertussis, as in Fig. 1, where the characters present in the freshly isolated strain degenerate at different rates. Fig. 2 shows a single character in a number of different strains, present in different potencies at first isolation and on culture in the laboratory degenerating at different rates and at different times.

What then is a Phase I organism? No exact definition is possible since this definition must depend to a great extent on opinion. Phase I was originally defined serologically. But Smolens et al. (1947), Kendrick et al. (1949) and Cohen 
(1949) have already reported variations in the agglutinability of freshly isolated strains, and also variations in the absorbing potencies of different strains which did not go hand in hand with their agglutinability (Smolens et al. 1947). The serological experiments reported in this paper support the view that freshly

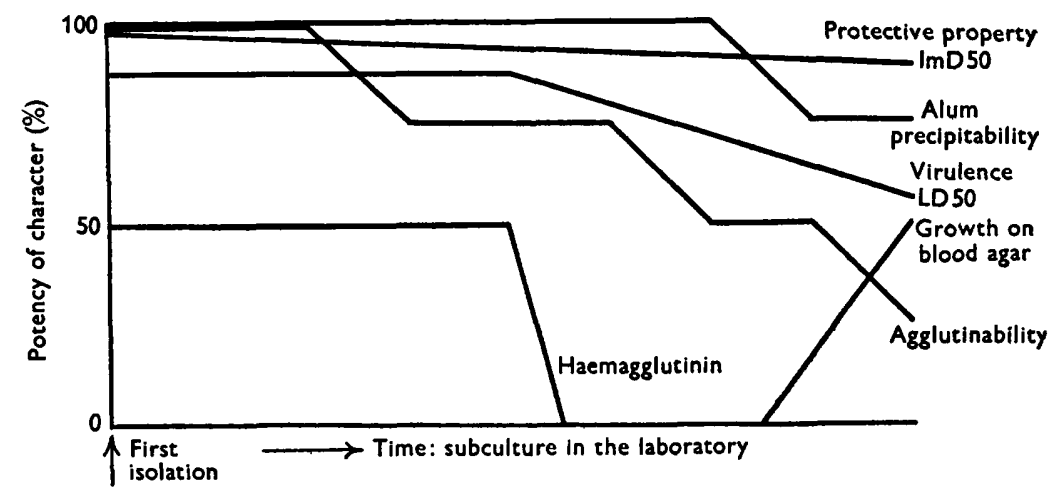

Fig. 1. Schematic representation of characters of a typical strain of $\boldsymbol{H}$. pertussis.

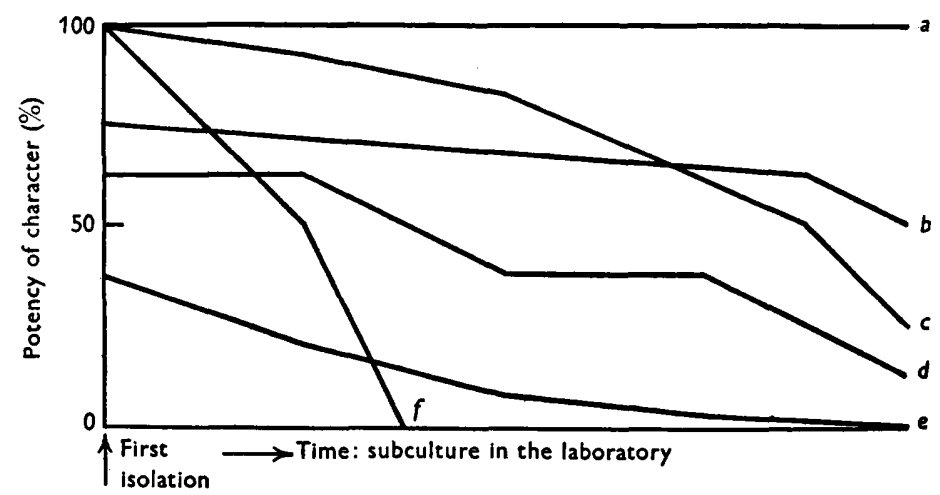

Fig. 2. Schematic representation of the same character in six strains of $\boldsymbol{H}$. pertussis.

isolated $H$. pertussis strains are serologically homologous. They also show that both the agglutinogen content of the cells as measured by agglutinin absorption and the agglutinability of the cells as measured by the agglutination test vary, and vary independently. The significance of the consistently low agglutination titres given by some strains is not clear. By agglutination titre and agglutinin absorbing power freshly isolated strains may be divided into four groups: strains of high agglutinability and high absorbing power, high agglutinability and low absorbing power, low agglutinability and high absorbing power and low agglutinability and low absorbing power; most strains fall into the first group; strains of low agglutinability are relatively rare probably comprising not more than $10 \%$ of strains isolated. Two of the three strains $I$ examined were of high absorbing power and one of low. 
It is obvious from cross-agglutination (Table 4) that low agglutinability is a function of the suspension and not of the antiserum, and that only one antigen is involved. Until the strain of low agglutinability and low absorption was found, I thought that strains of low agglutinability were strains with a lot of agglutinogen which for some reason required a high concentration of serum to agglutinate them. This, however, is not always so, and furthermore it is unlikely that strains which had been kept in the laboratory and were of lowered agglutinability, would increase their agglutinogen content. It is, however, difficult to understand why two strains with the same agglutinogen content as measured by agglutinin absorption should behave so differently in the presence of the same dilutions of agglutinating serum unless the variation in agglutinability is determined by factors other than the amount of agglutinogen on the cell surface, e.g. the distribution or availability of the receptors on the cell surface. Thus, if the active groups were clustered in discrete patches relatively distant from each other, more serum might be required to agglutinate them than if they were more evenly scattered. This hypothesis is supported, I think, by the behaviour of the old laboratory strains (Table 9). These strains all lost agglutinogen as measured by absorption before they lost agglutinability, which may mean that they first lost active groups and then these groups become 'thinned out' too far. The mechanism of agglutination in this group, of course, may be complicated by the appearance of another major antigen. The behaviour of the two strains of low agglutinability and high absorption may be due to 'bad siting', resulting in lack of availability of the active groups.

These experiments, at any rate, indicate that the serology of Phase $I$ is more complicated than originally thought and the expression 'agglutinates to titre' is not a valid criterion of a Phase I organism.

The word 'phase' with respect to Phase I H.pertussis, with its implication of phase as used in the salmonellas, has proved with time to be an unfortunate choice as a synonym for smooth or freshly isolated; it has served its useful purpose and should now be dropped. Leslie \& Gardner's original contention that the phases of $\boldsymbol{H}$. pertussis could revert has not, so far as I am aware, been confirmed.

'Freshly isolated' as a defining phrase is also open to objection, as some strains maintain their 'freshly isolated' characters for some time in the laboratory while others lose all or some rapidly.

The term 'virulent', usually meaning virulent for mice, is also open to objection, for though no avirulent, but otherwise typical strain, has yet been isolated, virulence is a quantitative term and the definition of avirulent must depend to some extent on dosage.

We fall back therefore on 'Smooth' as the best description of these strains; this was first suggested by Leslie \& Gardner (1931) and stressed by Shibley \& Hoelscher (1934) and by Lawson (1939), who pointed out that the dissociation of $\boldsymbol{H}$. pertussis was an example of the $S \rightarrow R$ variation with one or more intermediate stages, the exact characters of which will depend on the state the organism has reached.

The exact definition of the Smooth state with our present knowledge may be 
no easier, for we are dealing with an extremely variable organism, but we are employing a word in common bacteriological usage with a recognized meaning.

Freshly isolated strains of $\boldsymbol{H}$. pertussis accordingly fall into three groups, the 'ideal' or 'perfect' strains (which like other ideals may not exist in fact) containing all the characters in a fully developed state, 'normal' strains containing all the characters only some fully developed, but all adequately represented; and a third group in which one or possibly more characters are missing or are feebly displayed. All these strains will be $S$ mooth.

With a highly developed parasite like $H$. pertussis the final definition of a 'freshly isolated', 'virulent', 'smooth', 'Phase I' strain will probably depend on 'virulence for human beings'. When the factors responsible for this are known a final definition may be possible.

The author is indebted to the Directors of the Public Health Laboratory Service Laboratories at Cardiff, Colindale, Leeds, Manchester, Oxford and Poole for the supply of $\boldsymbol{H}$. pertussis strains; and to Miss M. P. D. Pile and Miss Betty Tredwell for technical assistance.

\section{REFERENCES}

Burnet, F. M. \& Timmins, C. (1937). Experimental infection with Haemophilus pertussis in the mouse by intranasal inoculation. Brit. J. exp. Path. 18, 83.

Cohen, S. M. (1949). Rep. N.Y. St. Dep. Hlth. Div. Lab. Res. p. 48.

Flosdorf, T. F., Dozois, T. F. \& Kimball, A. C. (1941). Studies with H. pertussis. V. Agglutinogenic relationships of the phases. J. Bact. 41, 457.

Kendrick, P. L., Eldering, G., Dixon, M. K. \& Misner, J. (1947). Mouse protection tests in the study of pertussis vaccine. Amer. J. publ. Hlth, 37, 803.

Kendrick, P. L., Updyke, E. L. \& Eldering, G. (1949). Comparison of pertussis cultures by mouse protection and virulence tests. Amer. J. publ. Hlth, 39, 179.

KeоGн, E. V. \& North, E. A. (1948). The haemagglutinins of Haemophilus pertussis. 1. Haemagglutinin as a protective antigen in experimental murine pertussis. Aust. J. exp. Biol. med. Sci. 26, 315.

Lawson, G. MCL. (1939). Immunity studies in pertussis. Amer. J. Hyg. 29 (Sect. B), 119.

Leshie, P. H. \& Gardner, A. D. (1931). The phases of Haemophilus pertussis. J. Hyg., Camb., 31, 423.

Pollock, M. R. (1947). The growth of $H$. pertussis on media without blood. Brit. J. exp. Path. 28, 295.

Portwood, L. M. (1946). Catalase activity of Haemophilus pertussis. J. Bact. 51, 265.

Reed, L. J. \& Muench, H. A. (1938). A simple method of estimating fifty per cent end-points. Amer. J. Hyg. 27, 493.

Shibley, G. S. \& Hoelscher, H. (1934). Studies on whooping cough. 1. Typespecific (S) and dissociation (R) forms of Haemophilus pertussis. J. exp. Med.60, 403.

Smolens, J., Mclaren, C. S., McAleer, D. S. \& Flavelx, E. H. (1947). The estimation of specific antigen in strains of Haemophilus pertussis. J. Immunol. 57, 361.

Standfast, A. F. B. (1951). The virulence of Haemophilus pertussis for mice by the intranasal route. J. gen. Microbiol. 5, 250.

Ungar, J. \& MUggleton, P. W. (1949). The relationship of the aluminium phosphate precipitation of organisms of Haemophilus pertussis strains to their other biological properties. J. gen. Microbiol. 3, 353.

(Received 6 January 1951) 